\title{
Gender stereotype and hostile sexism among young korean gamers based on teammate selection strategy and game style preferences
}

Doo Heon Song, Hae Kyung Rhee, Jeong Hoon Kim

Department of Computer Games, Yong-In SongDam College, Yong-in 17145, Korea



\section{INTRODUCTION}

According to the Korea Content Agency, the proportion of female game users is remarkably increasing in quantity especially in young age groups (under 30). In its 2015 yearly report, female teens play 71 minutes on weekdays and 102 minutes on weekends in average, compared to 74 minutes on weekends and 107 minutes on weekends of male teenage group. However, in the twenties, female gamers play 119 minutes on weekdays and 86 minutes on weekends that are 3 minutes more than male group of the same age [1]. Such trend is matched with North America [2] and Europe [3] in that female gamers are more than $40 \%$ in population and almost $50 \%$ in mobile platform. In other words, game playing is no more a "male-oriented" world. However, gaming culture is still a high huddle for female gamers. There exists a strong male gender stereotypes in that women are not considered as "true" or "hard-core" gamers. 쏘무 is based on the misconception that female gamers prefer simpler, less-competitive genre than male gamers [4] and many females have gender-rift that they stop playing games in their teenage period thus genre preferences are different from males [5, 6]. Although that pink game theory based on traditional sex role theory [7] is questioned by recent research [8], such stereotype makes female out of game culture [9].

Usually hostile environment against female gamers are represented as female characters being exaggerated and hypersexualized and it could lead to feelings of decreased self-esteem, depression, and other impacts on well-being for female gamers [10-14]. However, we believe that the gaming culture against female is more serious on what is happening in the gaming community. The stereotype of female gamers who 
is less skillful at gaming might be just a misconception in recent days. Even in Korea, young gamers feel that female gamers are perceived as "playing easy games" and "less skillful thus not appropriate for team play" [15]. A study that examined the gender differences in skills of 18,000 users in League of Legends games is very suggestive [16]. It reveals that the gender difference in winning rate and skills are found only among top $1 \%$ of highest skillful user groups and other than that there exists no notable and significant difference between males and females in game playing skills. Another large scale survey result indicates that there is no evidence that the innate gender difference makes skill difference in competitive games [17]. Rather, although females who play as much as males reach similar levels, there are many other reasons like social expectation and general hostile community environment that make females stop playing the game early. Thus, the stereotype of female players as inferior in performance is false but the perpetuation of this stereotype likely discourages female players from playing, thereby hindering their performance improvements and thus reinforcing the confounded relationship between gender and skill.

More serious problem arises very recently as the form of gender hatred in gaming community. In 2014, there was an online hate war called "Gamergate." Depression Quest, released in February 2013 by a female game developer, Joey Quinn, was well-received by game critics. Coincidentally, her ex-boyfriend depicted Joey Quinn's private life as having a close relationship with the top of the game critics personnel (later turned out to be a false story) and nuanced that such private life contributes her fame in game industry. It develops into feminist debate and misogyny among the game user group based on such speculation of inappropriate personal life of female for the success of business [18]. Unfortunately, it develops to the physical threats of a renowned feminist who stands for Joey Quinn and numerous lawsuits are undergoing.

Sexual harassment in game playing situation has been an important topic in the last decade. Especially in First-person Shooter (FPS) or massively multiplayer online role-playing games (MMORPGs) that require strategic team playing to win the game, frequently female players are attributed to the loss of the game without reason. As enumerated in [19], verbal harassment against female gamers happens very frequently and types of harassment is much more serious than anyone's thought. Such hostile in-game verbal sexual violence can cause emotional pain, low self-esteem, sleep disorders, anger and frustration, and traumatic syndrome in victims [20]. Thus, female gamers appear to require coping strategies to handle online harassment [21] such as gender swapping in game character selection [15]. The reason of such harassment is still unknown but the personal trait like high social domination orientation (SDO) and hostile sexism are main factors contributing such violent behavior [22] and similar result was found in Korea [23] using the same measure of sexual harassment in game playing developed by [19].

Such sexual harassment and sexual objectification also happened to Korean game community. In 2016, the largest Korean gaming enterprise Nexon cooperation launched the second sequel of its mega hit game Sudden Attack 2 that was expected to be a rival of Overwatch. However, Sudden Arrack 2 was heavily criticized with overly hypersexualized female characters' in-game behavior as shown in Figure 1 . Nexon finally ceased to service Sudden Attack2 after only 3 weeks and the $\$ 30$ Million investment went in the air.



Figure 1. Removed female character from sudden attack 2

Gender hatred in game playing community also became a social issue in 2017. While the gamergate incident happened in United States was an example of Misogyny, what happened in Korea in 2017 was an example of Misandry. A female YouTube Overwatch game broadcaster called Godgunbae used direct sexual

Gender stereotype and hostile sexism among young korean gamers based on teammate... (Doo Heon Song) 
abusive language to male players during game playing with no reason. Her broadcast induced a gender battle among her audiences and some male players investigate her physical identity and threaten her in public. Like Gamergate case, both parties call lawsuit against each other.

While such hostile sexism and masculine gender stereotyping make the gaming culture to the negative side among Korean gamers, there exist only a few researches how and why these negative aspects of gaming grow among gamers. Rather, several meaningful studies investigate what are female gamers' characteristics [24] and how they feel against aggressive harassment when their play skills become competitive [25]. Another limitation of these prior researches is that they surveyed only female gamers thus their studies are not sufficient to analyze how such gender stereotype/harassment actually happens in gaming community.

In this paper, we investigate how this gender stereotype and hostile sexism are represented in young Korean gamers' community by taking two surveys. The first survey is aimed at how young male and female gamers perceive each other as gamers based on game style preferences. If they have gender stereotype, the perceptions of one gender from the other gender would be different from their actual preferences. The second survey is more serious one. We take three different groups as survey subject groups for the same game Overwatch. One is most masculine online community called Ilbe (http://www.ilbe.com/ilbe) that is notorious as discriminating females and Womad (https://womad.life/ ) which is the exact opposite of Ilbe on gender issues in that male hatred is quite offensively expressed. The third online community group Inven (http://www.inven.co.kr/webzine/) is neutral in that most members visit for taking useful information on the game itself regardless of gender perspectives. By comparing with gamers from three online communities that have different perspectives on gender issues on teammate selecton preferences of the same game, we can see how gender stereotype and hostile sexism make gamers playing differently.

\section{SURVEY 1: GAME GENRE PREFERENCES AND MUTUAL PERCEPTIONS}

The first survey is done in November 2016 and the subjects are from many different online gaming communities such as Final Fantasy 14, Maple story, Overwatch, Mabinogy Heroes, EOS user café and a special community called Naver Female Gamers Café for listening female gamers' voices. The subject characteristics on daily game playing hours in weekdays are distributed as shown in Table 1.

Table 1. Subjects' faily game playing hours

\begin{tabular}{ccccc}
\hline Level & Male & Rate & Female & Rate \\
\hline$>3$ & 52 & $59.10 \%$ & 79 & $52.30 \%$ \\
$1 \sim 3$ & 19 & $21.60 \%$ & 42 & $27.80 \%$ \\
$<1$ & 17 & $19.30 \%$ & 30 & $19.90 \%$ \\
Total & 88 & $100 \%$ & 151 & $100 \%$ \\
\hline
\end{tabular}

As shown in Table 1, there is no significant difference in daily playing hours between genders as oppose to several western world surveys $[16,17]$. Thus, survey result on gender differences are not affected by playing time. In order to see if gender stereotype exists, we ask subject the following questions.(possibly multiple choices)

Question 1: What is your favorite game in style?

Question 2: What is your unfavorite game in style?

Question 3: What do you think would be male players' favorable game in style?

Question 4: What do you think would be male players' unfavorable game in style?

Question 5: What do you think would be female players' favorable game in style?

Question 6: What do you think would be female players' unfavorable game in style?

There are 8 different choices on above questions;

1) Well structured story

2) Splendid Graphics

3) Simple and easy game

4) Cute game

5) Horror

6) Socializing oriented

7) War-mode PvP(Player vs Player)

8) Customizing/Nurturing

Among 8 choices, if we take top 3 choices by gender on what they prefer/unprefer, what they think the same gender would prefer/unprefer, what the opposite gender would prefer/unprefer, we can find a strong gender stereotype as shown in Table 2 and Table 3. 
Table 2. Male's favorable/unfavorable game styles

\begin{tabular}{ccc}
\hline Rank & Male thinks males favor & Rate \\
\hline 1 & Splendid Graphics & $67.00 \%$ \\
2 & War-mode PvP & $59.10 \%$ \\
3 & Well Structured Story & $36.40 \%$ \\
Rank & Female thinks males favor & \\
1 & War-mode PvP & $77.50 \%$ \\
2 & Horror & $37.70 \%$ \\
3 & Social Game & $33.10 \%$ \\
Rank & Male actually favors \\
1 & Well Structured Story & $62.50 \%$ \\
2 & Splendid Graphics & $54.50 \%$ \\
3 & Customizing/Nurturing & $47.70 \%$ \\
Rank & Male actually disfavors \\
1 & Horror & $40.90 \%$ \\
2 & War-mode PvP & $36.40 \%$ \\
3 & Cute Games & $27.30 \%$ \\
\hline \multicolumn{3}{c}{}
\end{tabular}

Table 3. Female's favorable/unfavorable game styles

\begin{tabular}{ccc}
\hline Rank & Female thinks females favor & Rate \\
\hline 1 & Well Structured Story & $64.20 \%$ \\
2 & Cute Games & $61.60 \%$ \\
3 & Customizing/Nurturing & $53.00 \%$ \\
Rank & Male thinks females favor & \\
1 & Simple \& Easy & $61.40 \%$ \\
2 & Well Structured Story & $53.40 \%$ \\
3 & Social Game & $51.10 \%$ \\
Rank & Female actually favors \\
1 & Well Structured Story & $78.80 \%$ \\
2 & Splendid Graphics & $57.60 \%$ \\
3 & Customizing/Nurturing & $51.00 \%$ \\
Rank & Female actually disfavors & \\
1 & War-mode PvP & $71.50 \%$ \\
2 & Horror & $40.40 \%$ \\
3 & Splendid Graphics & $31.80 \%$ \\
\hline
\end{tabular}

Strikingly, males and females favor the same game style in order in Top 3 (they actually favor) as well structured story, splendid graphics, customizing/nurturing in order. However, males expect females would prefer simple \& easy, well structured story, social games in order. Actually female subjects prefer simple and easy games the least on question 1 (only $4 \%$ picks that style). Similarily, females also have misconceptions on male players in that male gamers would prefer war-mode PvP and horror games but actually they do not prefer them. Even horror games and war-mode PvP is the top two unfavorable game style among male players. One interesting point is that male subjects also expect male players would prefer war-mode PvP which is not true. In this first survey, we can witness that there exists a strong gender stereotype from both sides and surprisingly their favorite game styles are not different at all.

\section{SURVEY 2: TEAMMATE SELECTION PREFERENCES FROM DIFFERENT GENDER ATTITUDE GROUPS}

The second survey is designed to see if community groups having different attitudes on opposite gender would favor differently in partner selection and taking roles in the same games especially in team battle games like Overwatch. Thus, we take two groups having extreme attitude (hatred) in opposite gender and one neutral group as a control group. The Ilbe' community (original meaning is Daily best Archive) has been publicly revealing its extreme righteous political tendencies since the 2012 presidential campaign, and the number of members are estimated as hundreds of thousands at one time [26]. Ilbe, however, also has addressed the problem by directly describing hatred and mockery against females in that they are inferior to males and generalize female as a group of economically 'exploitation' over men with collateral intimacy [27]. In gaming community, female gamers can easily viewed as 'Queen bee' meaning that she takes advantage as being a female as having high level male friend to obtain higher rank or favorable items with no effort. Womad is a radical feminist, homophobia community born from the extremist females' anger on the random murder of a female by a young male who believes he was rejected by females with no reason thus kill a female as a revenge, so called Kangnam station random female murder [28]. Thus, basically Womad express an extreme hatred against males. The number of members are not publicized but estimated as having tens of thousands of young females. They often have off-line demonstrations on gender issues in public.

Interestingly, both extreme gender attitude communities have common game playing sector Overwatch, a team-based multiplayer FPS developed and published by Blizzard Entertainment and released on May 24, 2016. In a team of six players, Overwatch heroes are divided into different roles such as dealers, tankers, and healers, and the heroes have their own ultimate special skills designed for such roles [29]. The dealer plays the role of the main character in the team, but the rear support, or healer, is also important for the team's victory. And those who seem to lack skills or want to be less responsible for winning or losing usually takes 'sub' role. However, disagreements often arise between gamers about team composition and the outcome of the match and often it develops to attack female gamers in the community [23, 30]. Since both groups are far extreme, we also take a third group as a controlled neutral attitudes on gender issues. Inven is a community that gamers exchange gaming tips and sharing information. Although usually male members are in majority in that community, that does not assume that Inven is similar to Ilbe. Usually Inven members are focused on game skills and information exchange.

In this survey, we investigate how the Overwatch player from three different social community prefer to make other player taking specific role in the game. The questions are as following;

1) What role do you think male (female) gamer is appropriate in your team?

2) What would be your strategy to pick a team player for dealer (tanker, healer) if you have the privilege to make a team at your will?

Gender stereotype and hostile sexism among young korean gamers based on teammate... (Doo Heon Song) 
The first question asks how the subject matches gender-role in the game of Overwatch. Meanwhile, the second question asks to pick a specific characteristics of the team player for the specific role. If a subject does not have gender stereotype or sexism, the answer will be about the skills of the game regardless of the gender. The survey was done in June 2018. The Google docs based questionnaire was posted at three online communities (Ilbe, Womad, Inven) for a week. Table 4 summarizes the distribution of subjects' gender and age group with respect to three communities. Over 95\% of subjects (64 out of 67) are under 30 in age. As expected from the characteristics of the far extreme attitude of the community, over $90 \%$ of subjects from Ilbe was male and over $88 \%$ of the subjects from Womad was female. The controlled neutral group Inven shows 7: 3 rate of male vs female. There was no significant differences on game rank with respect to the subjects' affiliated communities. On question 1, subjects' answers are summarized as shown in Table 5.

Table 4. Subjects by gender, age, and community

\begin{tabular}{ccccc}
$\begin{array}{c}\text { Group/ } \\
\text { Age }\end{array}$ & $\begin{array}{c}10 \sim \\
19\end{array}$ & $\begin{array}{c}20 \sim \\
29\end{array}$ & $\begin{array}{c}> \\
3\end{array}$ & $\begin{array}{c}\text { Tot } \\
\text { al }\end{array}$ \\
\hline $\begin{array}{c}\text { Ilbe- } \\
\text { Male }\end{array}$ & 2 & 33 & 2 & 37 \\
$\begin{array}{c}\text { Ilbe- } \\
\text { Female } \\
\text { Ilbe- } \\
\text { Total }\end{array}$ & 4 & 0 & 1 & 5 \\
$\begin{array}{c}\text { Inven- } \\
\text { Male }\end{array}$ & 1 & 11 & 0 & 12 \\
Inven- & 1 & 4 & 0 & 5 \\
$\begin{array}{c}\text { Female } \\
\text { Inven- } \\
\text { Total }\end{array}$ & 2 & 15 & 0 & 17 \\
Womad- \\
Male
\end{tabular}

Table 5. Roles appropriate for male (female)?

\begin{tabular}{cccc}
\hline $\begin{array}{c}\text { Male's } \\
\text { Role }\end{array}$ & $\begin{array}{c}\text { Ilb } \\
\text { e }\end{array}$ & $\begin{array}{c}\text { Inve } \\
\mathrm{n}\end{array}$ & $\begin{array}{c}\text { Wom } \\
\mathrm{ad}\end{array}$ \\
\hline Dealer & 25 & 9 & 5 \\
Tanker & 6 & 0 & 1 \\
Healer & 1 & 0 & 1 \\
Sub & 6 & 3 & 1 \\
Indiffer & 4 & 5 & 0 \\
ent & & & 8 \\
Total & 42 & 17 & 8 \\
Female' & Ilb & Inve & Wom \\
s Role & $\mathrm{e}$ & $\mathrm{n}$ & $\mathrm{ad}$ \\
Dealer & 2 & 5 & 3 \\
Tanker & 0 & 1 & 0 \\
Healer & 37 & 6 & 3 \\
Sub & 3 & 1 & 2 \\
Indiffer & 0 & 4 & 0 \\
ent & & & 8 \\
Total & 42 & 17 & 8 \\
\hline
\end{tabular}

Subjects from Ilbe thinks males for dealer $(60 \%)$ and females for healer $(88 \%)$. This rate is far extreme compared with Inven (53\% for male as dealer vs $35 \%$ for female as healer) and Womad (63\% vs $37 \%$ ). Thus, Ilbe gamers are regarded as having male oriented gender stereotype more than other communities. On question 2, subjects' answers are summarized as shown in Table 6.

Table 6. What might be the main criteria to pick a team member as dealer?

\begin{tabular}{cccc}
\hline Dealer & Ilbe & Inven & Womad \\
\hline High winning rate \& Kill/Death & 22 & 15 & 7 \\
High Specification & 15 & 12 & 5 \\
Male & 11 & 1 & 0 \\
Female & 1 & 0 & 6 \\
Fun Guy & 5 & 2 & 0 \\
Total & 32 & 30 & 23 \\
Responded & 28 & 17 & 8 \\
\hline
\end{tabular}

If a subject has no sexism on taking a dealer teammate, one would pick a member with high winning rate, high Kill/dealer rate, or high rank/specifications. Thus, the point is how much rate they pick a teammate with respect to the gender. $38 \%$ of Ilbe (11 males and 1 female) and $26 \%$ of Womad (6 females) picks with respect to the gender whereas Inven, the controlled group, has almost no pick (1 out of 30 answers).

Similarly, subjects from Ilbe (23\%) and Womad (31\%) picks based on the gender whereas almost no (2 out of 29) picks from Inven for Tanker teammate. For healer, Ilbe subjects picks only $15 \%$ based on the gender whereas they think females are appropriate for the healer role at $88 \%$ rate from Table 5. That implies Ilbe subjects have innate negative sexism on females. Throughout the question 2, subjects from Womad continuously pick females as specific roles at $30 \%$ rate and that implies Womad gamers also have gender stereotype at a significant rate. 


\section{CONCLUSION}

In this paper, we investigate how sexism and gender stereotype are involved in game playing among young Korean gamers. We take two different surveys for that purpose. In the first survey, subjects are asked for their favorable/unfavorable game styles with respect to the gender and themselves. Surprising result shows that male and female gamers have almost same preferences in style - story, graphics, customizing in that order. However, they think differently on the opposite gender. Female subjects think male gamers would like PvP and horror games that actually male gamers say 'unfavorable'. Male subjects also exhibit strong gender stereotype in that female gamers would like simple and easy games and social games which are least favorable ones from female subjects' answers. Thus, strong gender stereotype exists for both genders among young Korean gamers.

In the second survey, we try to investigate if such gender stereotype affects the game playing strategy. We take subjects from two extreme groups - Ilbe as 'almost mysogyny' community, womad as 'almost misandry community' - that are regarded as having hostile sexism as a group. The controlled group Inven is a gamers community that is aimed for sharing game playing information thus members of Inven are not directly involved in hostile sexism. Since all three community have Overwatch subgroup, we ask how the subject would pick the team members as a specific role - dealer, tanker, healer. The result confirms that Ilbe and womad groups show a strong sexism/gender stereotype as expected in game playing strategies.

According to the ambivalent sexism theory [31], the sexism exbited in these surveys is a hostile sexism that sees women as incompetent, overly emotional, and trying to manipulating men to gain power over men. The implication of the second survey is that this hostile sexism may not be induced by gaming itself as agreeing with [32] and disgreeing with [33] in that the hostile sexism in game playing is not directly related to the amount of game playing experiences but other social factors. The lmitation of this research is that the far extreme social communities are not that open to accept such gender related surveys yet thus the number of subjects participated in this paper are quite limited therefore the resilt should be carefully generalized.

\section{REFERENCES}

[1] Korea Creative Contents Agency, White Paper on Korean Games, 2015.

[2] Entertainment Software Association, 2014 sales, demographic and usage data: Essential facts about the computer and video game industry, Washington, DC: Entertainment Software Association; 2014.

[3] Interactive Software Federation of Europe. Videogames in Europe: consumer study. 2012.

[4] Paaßen B, Morgenroth T, Stratemeyer M. "What is a true gamer? The male gamer stereotype and the marginalization of women in video game culture". Sex Roles: vol. 76, no. 7-8, pp. 421-35, 2017. doi: 10.1007/s11199-016-0678-y

[5] Agosto D. Girls and gaming. A summary of the research with implications for practice, Teacher Librarian: TL Magazine, vol. 31, no. 3, pp. 1-8 (online). 2004.

[6] Chou C, Tsai MJ, Gender differences in Taiwan high school students' computer game playing, Computers in Human Behavio, vol.23, no. 1, pp. 812-824, 2007.

[7] Koenig AM, Eagly AH, "Evidence for the social role theory of stereotype content: Observations of groups' roles shape stereotypes," Journal of Personality and Social Psychology, vol. 107, no. 3, pp. 371-392, 2014.

[8] Van Reijmersdal EA, Jansz J, Peters O, Van Noort G. "Why girls go pink: Game character identification and gameplayers' motivations", Computers in Human Behavior, vol. 29, no. 6, pp. 2640-2649, 2013.

[9] Vermeulen L, Van Bauwel S, Van Looy J. "Tracing female gamer identity. An empirical study into gender and stereotype threat perceptions”. Computers in Human Behavior, vol. 71, pp. 90-98, 2017. doi: 10.1016/j.chb.2017.01.054

[10] Lopez-Fernandez O, Williams, AJ, Griffiths, MD, Kuss, DJ. "Female gaming, gaming addiction, and the role of women within gaming culture: A narrative literature review". Frontiers in psychiatry, 2019; 10(online).

[11] Fox K. Tang WY, "Sexism in online video games: The role of conformity to masculine norms and social dominance orientation", Computers in Human Behavior, vol. 33, pp. 314-320, 2014.

[12] Martins N, Williams DC, Harrison K, "Ratan RA. A content analysis of female body imagery in video games". Sex role, vol. 61, no. 11-12, pp. 824, 2009.

[13] Driesmans K, Vandenbosch L, Eggermont S. "Playing a videogame with a sexualized female character increases adolescents' rape myth acceptance and tolerance toward sexual harassment". Games for health journal, vol. 4, no. 2, pp. 91-94, 2015.

[14] Matthews NL, Lynch T, Martins N. "Real ideal: investigating how ideal and hyper-ideal video game bodies affect men and women." Computers in Human Behavior, vol. 59, pp. 155-64, 2016. doi: 10.1016/j.chb.2016.01.026

[15] Song DH, Park S, Yang SW, Yang Y, Won K. "Gender Differences and Gender Stereotype in Play Style among Young Korean Gamers", Journal of the Korea Institute of Information and Communication Engineering, vol. 21, no. 1, pp. 72-81, 2017.

[16] Ratan RA, Taylor N, Hogan J, Kennedy T, Williams D. "Stand by your man: An examination of gender disparity in league of legends", Games and Culture, vol. 10, no. 5, pp. 438-462, 2015.

[17] Shen C., Ratan R, Cai YD, Leavitt A. "Do men advance faster than women? Debunking the gender performance gap in two massively multiplayer online games". Journal of Computer-Mediated Communication, vol. 21, no. 4, pp. 312-329, 2016.

Gender stereotype and hostile sexism among young korean gamers based on teammate... (Doo Heon Song) 
[18] The sexist crusade to destroy game developer Zoe Quinn, The Daily Dot, Available: https://www.dailydot.com/parsec/zoe-quinn-depression-quest-gaming-sex-scandal/

[19] Tang WY. Sexual harassment in online videogames: What we found so far. Age. Available : http://www.gamasutra.com/blogs/WaiYenTang/20160418/270538/Sexual_harassment_in_online_videogames_What _we_found_so_far.php

[20] Larsen SE, Fitzgerald, "PTSD symptoms and sexual harassment: The role of attributions and perceived control", Journal of Interpersonal Violence, vol 26, no. 13, pp. 2555-2567, 2011.

[21] Fox J.Tang WY. "Women's experiences with general and sexual harassment in online video games: Rumination, organizational responsiveness, withdrawal, and coping strategies", Newmedia \& Society, vol. 18: online, 2016.

[22] Tang WY, Fox J. "Men's harassment behavior in online video games: Personality traits and game factors", Aggressive behavior, vol. 42, no. 6, pp. 513-521. 2016.

[23] Song DH, "Analysis of Korean Gamers' Personality Patterns with respect to the Victim/Attacker of the Misogyny and the Misandry in Game Playing", Journal of the Korea Institute of Information and Communication Engineering, vol. 22, no. 11, pp. 1481-88, 2018.

[24] Shim SA Jung JW. "A study on the characteristics of female gamers - Focusing on women in 20's", Journal of Korean Society for Computer Games, vol 27, no. 1, pp. 43-54, 2014.

[25] Jeon G, "A study of Women in Digital Games and Their Gaming". Journal of Cyber communication, vol. 22, no. 7m, pp. 83-117, 2007.

[26] Kim H. "Dynamics of Cyber Hate and Effervescence; Focusing on the Korean Internet Community 'IlbeJoejangso"”, M.A. Thesis, Seoul National University, Aug. 2014.

[27] Yun B. "Ilbe and Misogyny: Ilbe exist everywhere and nowhere", Radical Review, vol. 57, pp. 33-56, 2013.

[28] Goh B. "Defining 'Women' through the Denial of Solidarity: the Case Study of the WOM AD and TERF after the Split of the Megalia", M. A. Thesis, Ewha Women's University, Feb. 2018.

[29] Rhee HK, Song DH, Kim JH, "Comparative analysis of first person shooter games on game modes and weaponsmilitary-themed, overwatch, and player unknowns' battleground", Indonesian Journal of Electrical Engineering and Computer Science (IJEECS); vol. 13, no.1, pp. 116-122, 2019.

[30] Beom Y, Lee B, Lee Y. "<Overwatch>, in Different Voices.-An Analysis of Violent Speeches toward Female Game Players in <Overwatch>”, Public Interest and Human Rights, pp. 283-337, 2017.

[31] Glick P, Fiske ST. "The ambivalent sexism inventory: Differentiating hostile and benevolent sexism", Journal of Personality and Social Psychology, vol.70, pp. 491-512, 2012. DOI: 10.1037//0022-3514.70.3.491.

[32] Breuer J, Kowert R, Festl R, Quandt T. "Sexist games= sexist gamers? A longitudinal study on the relationship between video game use and sexist attitudes", Cyberpsychology, Behavior, and Social Networking; vol. 18, no. 4, pp. 197-202, 2015.

[33] Stermer SP, Burkley M. "SeX-Box: exposure to sexist video games predicts benevolent sexism”, Psychology of Popular Media Culture, vol. 4, no. 1, pp. 47-55, 2015.

\section{BIBLIOGRAPHY OF AUTHORS}
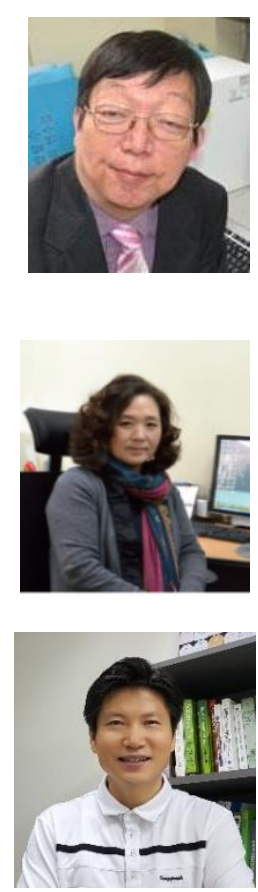

Prof. Doo Heon Song received his B.S. from Seoul National University, Korea in 1981 and M.S. from the Korea Advanced Institute of Science and Technology in 1983 in Computer Science. He received his Ph.D. Certificate in Computer Science from the University of California at Irvine, USA in 1994. He has been a professor at Department of Computer Games, Yong-in SongDam College, Korea, since 1997. His research interests include machine learning, artificial intelligence, fuzzy systems, medical image processing, and computer game design. He is currently the associate editor of Journal of Information and Communication Convergence Engineering

Dr. Hae Kyung Rhee obtained her B.S. from Sungsil University, Korea in 1979, M.S. from University of Illinois at Urbana-Champaign, USA in 1985, Ph. D. at Sungkunkuan University, Korea in Computer Science in respectively. She has been a professor at Department of Computer Games, Yong-in SongDam College, Korea, since 2001. Her research area includes database development, data modelling in Game design, Information Security.

Prof. Jeong Hoon Kim received his B.S. from Seoul University, Korea in 1991 and M. S. from Yonsei University, Korea in 1994 in Computer Science. He was one of key developers of online MMORPG Lineage tournament from NCSoft during 1999-2001 and developed several mobile games in Softgen. Inc. until 2003. He joined with faculty members of Department of Computer Games, Yong-in SongDam College, Korea since 2003. His research interests include developing mobile games and online games. 